\title{
AUTECOLOGY AND THE SPECIES PROBLEM IN FUCUS
}

\author{
By Elsie M. Burrows, B.Sc., Ph.D. \\ Department of Botany, Liverpool University \\ and Sheila Lodge, B.Sc., Ph.D. \\ Marine Biological Station, Port Erin
}

(Text-figs. I-6)

On the rocky shores of the British Isles three species of Fucus are commonly found as components of the intertidal algal belt, namely, $F$. spiralis L., $F$. vesiculosus L. and $F$. serratus $\mathrm{L}$. A fourth species, $F$. ceranoides L., occurs in places subject to the influence of fresh water but, although it may be important in connexion with the interacting processes to be described below, $F$. ceranoides is omitted from the present discussion because as yet too little is known of its autecology. Under the conditions prevailing in the characteristically zoned algal flora of an undisturbed region of a rocky coast, descriptions of the three species can be applied which fairly effectively distinguish one from the others. The chief characters used for this purpose are shown in Table I.

Other characters also help in separating the three species, as, for example, methods of branching and texture of the frond, and the numbers and positions of cryptostomata; but these characters can be greatly modified by variations in environmental conditions and are difficult to estimate objectively.

\section{HybRIDS BeTWEen FUCUS SPECIES}

Hybrid sporelings between pairs of these species have been produced experimentally a number of times. Thuret (1854) obtained hybrid sporelings by fertilizing eggs of $F$. vesiculosus by antherozoids of $F$. serratus, but failed to make the reciprocal cross. Kniep (1925) carried out the crossing in both directions and obtained $4 \%$ development from eggs of $F$. vesiculosus and antherozoids of $F$. serratus and $2 \%$ for the reciprocal cross. He obtained much higher percentages of sporelings by crossing $F$. spiralis L. (given as F. platycarpus Thur.) with $F$. vesiculosus, 70 and $100 \%$ respectively using eggs of $F$. spiralis and $F$. vesiculosus with antherozoids of the opposite species. In February 1949 the present authors obtained 9I \% segmentation in eggs of $F$. serratus fertilized with antherozoids of $F$. vesiculosus and $99 \%$ segmentation for the reciprocal cross. No examples are on record of hybrid plants being grown 
in culture but this may be due to the difficulty of culturing sporelings of Fucus species under laboratory conditions.

The present authors have had some success with trial cultures of Fucus sporelings on sterile bricks cemented to the shore. Eggs were released on to the bricks and fertilized by releasing antherozoids over them. The eggs were planted in straight lines for ease of recognition, and the sporelings grown in the laboratory in running sea water for I or 2 months, by which time they could easily be seen with the naked eye. The bricks were then cemented to chosen positions on the shore and no difficulty was found in following the growth of the sporelings. On the experimental bricks it was several months before any further sporelings appeared. One difficulty with the method at present is that plantings must be carried out on a large scale to allow for loss of bricks in heavy seas.

Table I. Characters used in the Separation of Fucus spiralis, FUCUS VESICULOSUS AND FUCUS SERRATUS

\begin{tabular}{|c|c|c|c|}
\hline Character & F. spiralis & F. vesiculosus & F. serratus \\
\hline $\begin{array}{l}\text { Frond: } \\
\text { Shape } \\
\text { Vesicles } \\
\text { Margin }\end{array}$ & $\begin{array}{l}\text { Spirally twisted } \\
\text { None } \\
\text { Even }\end{array}$ & $\begin{array}{l}\text { Flat } \\
\text { Present } \\
\text { Even }\end{array}$ & $\begin{array}{l}\text { Flat } \\
\text { None } \\
\text { Serrated }\end{array}$ \\
\hline Receptacles: & & & \\
\hline Shape & Rounded & $\begin{array}{l}\text { Ellipsoidal-elongate } \\
\text { pointed }\end{array}$ & Extended growth \\
\hline $\begin{array}{l}\text { Sterile rim } \\
\text { Inflation } \\
\text { Sex }\end{array}$ & $\begin{array}{l}\text { No dichotomies } \\
\text { Present } \\
\text { Inflated } \\
\text { Hermaphrodite }\end{array}$ & $\begin{array}{l}\text { I-2 dichotomies } \\
\text { No definite rim } \\
\text { Inflated } \\
\text { Dioecious }\end{array}$ & $\begin{array}{l}\text { Several dichotomies } \\
\text { No definite rim } \\
\text { Not inflated } \\
\text { Dioecious }\end{array}$ \\
\hline
\end{tabular}

Since hybrid sporelings can be produced quite readily in culture, it might be assumed that they are equally readily formed in the sea, yet very few instances have been recorded of naturally occurring hybrids. Sauvageau (I909), Stomps (I9II) and Kniep (I925) recorded plants with characters intermediate between $F$. spiralis and $F$. vesiculosus and assumed that these plants were hybrids. Sauvageau (1909) also described a series of plants intermediate between $F$. vesiculosus and $F$. serratus. The appearance of these plants varied with the position on the shore, approaching $F$. vesiculosus towards the upper limit and F. serratus towards the lower limit of distribution. Fritsch (1945, pp. 379-80) remarks, however, 'It still remains doubtful whether these and other transitional types, found at the limits of the zones occupied by the various species of Fucus, are actually hybrids or habitat forms'.

Several authors have remarked on this absence of satisfactory hybrid records (Sauvageau, 1909; Kniep, 1925; Fritsch, 1945), and the reason for their relative absence under natural conditions has been attributed to one or other of two causes. (i) Hybrids may really be absent and the suggestion has been put forward that the hybrid sporelings, although formed, find the habitat 
unsuitable or are unable to compete with the parent species (Kniep, I925). (ii) Hybrids may really be more common on the shore than is realized, but the extreme variation within the individual species makes it difficult to recognize them with certainty (Sauvageau, I909).

Thus the three species appear to be fairly distinct from one another, and in addition to the morphological diagnostic features given, others have been used to delimit them as, for example, specific habitat requirements-position on the shore in relation to tide-levels and all that this involves in terms of exposure to desiccation, changing light intensities, temperature and other factors. $F$. spiralis is normally found in the highest position on the shore where it may be left exposed for several days at a time during neap tides; $F$. vesiculosus occupies the mid-tide zone for which it competes with Ascophyllum nodosum, and where it is alternately exposed and submerged for each tidal period; Fucus serratus occupies the lowest level, and, although part of the zone may be uncovered during the tidal period, other parts may be more or less continually covered.

Recent ecological work has shown, however, that the range of requirements for each of these species is not as limited as was previously supposed. As a result of clearance experiments carried out at different levels on the shore in the south part of the Isle of Man it was shown that removal of one species may allow extension of the ranges of others. In this connexion Ascophyllum is important because it dominates the mid-tide region and influences the ranges of all three Fucus species. An area cleared in the upper part of the Ascophyllum zone, in August I945 at the time when Fucus spiralis was fruiting, became covered by sporelings of the latter species and these persisted and fruited the following year (Burrows, I947). Further, truncation in December 1943 of Ascophyllum plants to a length of $10 \mathrm{~cm}$. over an area of shore allowed development of sporelings of both Fucus vesiculosus and F. serratus which were present on the rock surface, but which had been prevented from developing by the presence of the Ascophyllum. The effect of such truncation on the fucoid component of the area is seen in an analysis of the populations of sample $\frac{1}{2} \mathrm{~m}$. quadrats taken towards the end of 1945 , one with its lower edge I m. vertically below M.S.L. and the other with its lower edge on M.S.L. In each the adjacent $\frac{1}{2} \mathrm{~m}$. of uncut Ascophyllum area was analysed in order to obtain an estimate of the original composition of the population. Figs. I and 2 show percentage frequency distributions for lengths of plants of Fucus vesiculosus and $F$. serratus in the sample quadrats. Both species were initially present mainly as sporelings beneath the Ascophyllum; at the upper level-zone Isporelings of Fucus vesiculosus were more plentiful and at the lower levelzone II-those of $F$. serratus. In both zones the effect of the removal of the long shading fronds of Ascophyllum was to allow continued development of plants of Fucus serratus and F. vesiculosus and to allow also increase in their numbers. 


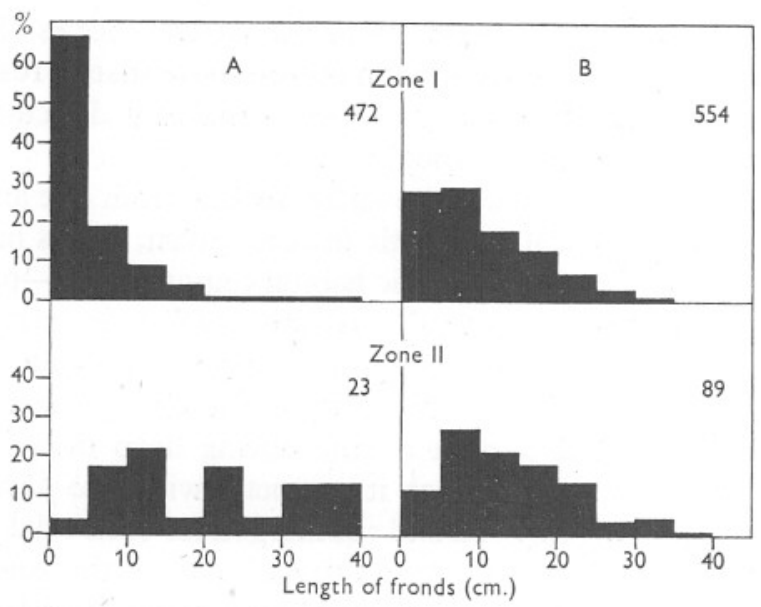

Fig. I. Growth of Fucus vesiculosus 20 months after cutting Ascophyllum frondage. A, uncut control; B, Ascophyllum cut to $10 \mathrm{~cm}$. Percentage frequency (vertical) of various lengths of Fucus vesiculosus fronds (horizontal). The numbers inset give the total number of plants in the sample.

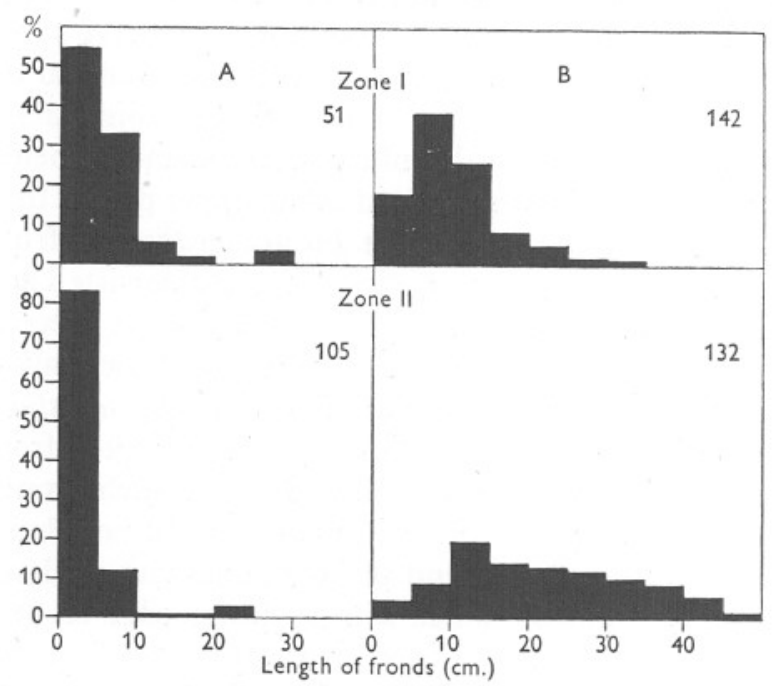

Fig. 2. Growth of Fucus serratus 20 months after cutting Ascophyllum frondage, as in Fig. I.

\section{Hybrids ON A RECOLONIZEd STRIP}

The above facts emphasize the importance of competition in limiting the range of a species. Of extreme interest in this connexion were the results of an experiment carried out on the shore at Port St Mary, Isle of Man (Jones, I948). A strip, Io m. wide, extending from just below M.H.W.N.T. to just above M.L.W.S.T., was cleared of limpets and larger algal growth. The experiment was 
designed to determine the influence on the growth of algae of the large numbers of limpets occurring on the limestone ledges which here bear only an extremely scattered algal population. The area cleared was sufficiently large to eliminate any possible influence of surrounding plants of the parent species. The subsequent development of a dense band of vegetation on the cleared strip has been described by Jones (1948), and the first stages in the succession of algal growth by Lodge (1948). An analysis of the vegetation on the strip after 3 years' growth has been carried out by the present authors. The resultant flora proved to be very different from that expected from previous conceptions of the fucoid zonation of a rocky coast. On the whole, $F$. serratus proved to be more plentiful on the lower part of the strip and $F$. vesiculosus on the upper part, but both occurred at all levels. F. spiralis formed no distinct zone but was present in small quantities at all levels down to low-water mark. In this position it was very luxuriant, the fruiting plants having a bushy appearance and a length up to $2 \mathrm{ft}$. However, the large majority of Fucus plants could not be assigned to any one species.

If, as was suggested by Kniep, it is the factor of competition with the parent species which eliminates hybrid sporelings from the shore, then in the absence of competition on a recently cleared area, the occurrence of hybrids might reasonably be expected. An analysis of sample square metres taken from various levels on the strip showed the presence of large numbers of plants which were intermediate in their characters between $F$. spiralis and $F$. vesiculosus (Fig. $3 b$ ) and between F. vesiculosus and F. serratus (Fig. $3 a$ ). For the hybrid analysis Anderson's method (1936), devised for the analysis of hybrid populations of Tradescantia, was adopted. The method is briefly as follows-given a number of readily ascertainable characters differing between two species $A$ and $B$, for each of these characters an individual plant is given a score, $a, b$ or $i$ depending on whether, in this respect, it follows one or other species or is intermediate between the two. This qualitative scoring can be made quantitative by numerically weighting each of the letters and when the total value for each plant has been computed the indices thus found can be summarized as a frequency distribution. The importance of certain specific characters can be emphasized by appropriate weighting.

\section{Characters USED IN THE ANALysis OF Hybrids BETWEEN FUCUS SPIRALIS AND FUCUS VESICULOSUS}

Five characters were considered as readily ascertainable and were used in the separation of $F$. spiralis and $F$. vesiculosus: (i) Vesiculation of the thallus. (ii) Spiral twisting of the thallus. (iii) Receptacle shape. (iv) Presence or absence of a sterile rim to the receptacle. (v) Hermaphrodite or dioecious condition of the receptacle.

Of these characters, nos. (i) and (v) were considered as of more importance than the others and were more heavily weighted accordingly. 


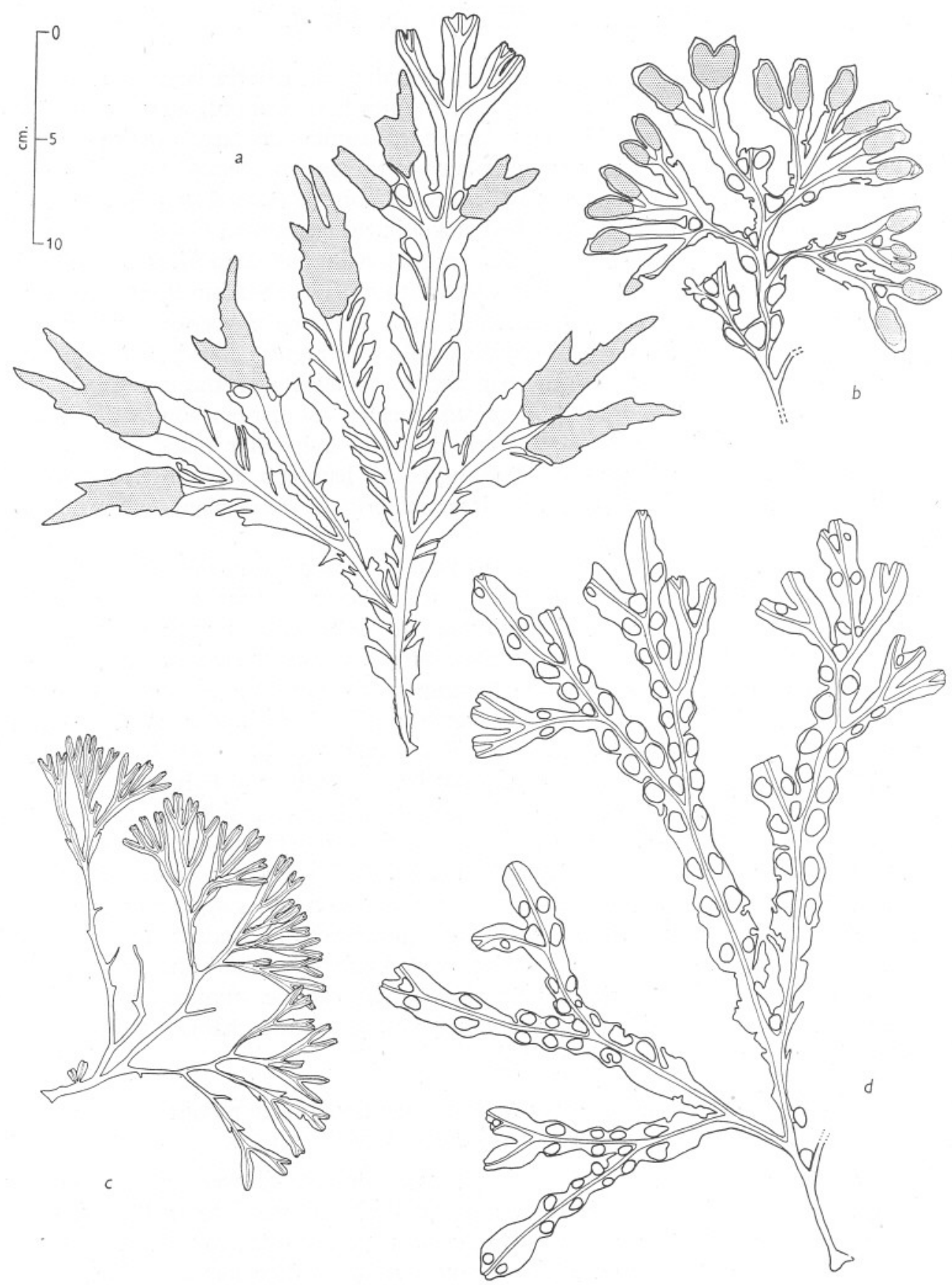

Fig. 3. a, Fucus vesiculosus $\times$ F. serratus hybrid, from the experimental strip, Port St Mary, Isle of Man. $b, F$. spiralis $\times F$. vesiculosus hybrid, with vesicles and rimmed receptacles, from Isle of Man. c, F. vesiculosus var. evesiculosus Cotton, from the outer side of the breakwater, Port Erin, Isle of Man. $d, F$. vesiculosus var. vadorum Aresch., from Derby Haven, Isle of Man. 
Before characters can be used in a hybrid analysis it is necessary to examine the degree of variability in respect of each character shown by the parent species, because on this depends its reliability. Both species show extensive variation in relation to a number of characters and, for $F$. vesiculosus especially, a large number of varieties have been described.

\section{Vesiculation of the Thallus as a Diagnostic Character}

Of the two characters, nos. (i) and (v) considered as of greatest importance in separating $F$. spiralis and $F$. vesiculosus, that of the hermaphrodite or dioecious condition is probably the most reliable. It may, as Stomps suggests, be the only one. There is little, if any, evidence that it is a character affected by changes in environmental conditions. Vesiculation of the thallus would appear, however, to be profoundly affected by such changes, and must therefore be considered in some detail. It appears certain from an examination of plants of $F$. vesiculosus found growing under varying degrees of exposure to severe wave action on the south coast of the Isle of Man, that the formation of vesicles is directly correlated with the roughness of the water washing them during the intertidal period. On very exposed areas, such as the outer side of the Breakwater at Port Erin, and at the extreme end of the Langness Peninsula, vesicles are almost entirely lacking. Fig. $3 c$ illustrates a typical plant from the former situation, which is probably to be identified as $F$. vesiculosus var. evesiculosus Cotton. With increased shelter from the direct breaking force of heavy waves (and quite a small boulder effectively placed will suffice to provide it), vesicles appear and increase in numbers, becoming well developed in quiet waters. The extreme form is that distinguished as var. vadorum Aresch. which has rows of closely placed pairs of vesicles and which only occurs in the quietest inlets (Fig. $3 d$ ). The variation in form and behaviour of $F$. vesiculosus under varying degrees of exposure will be discussed in a separate paper: here it suffices to record merely the distribution of vesiculate and evesiculate plants in relation to degrees of exposure. Similar distributions have been described by Kylin (1907) for the west coast of Sweden, by Cotton (I9I2, pp. 23-6) for Clare Isiand, by Richard (1925) for an area on the coast of Belgium, and by Knight \& Parke (1950) for the Devon, Manx and Argyll coasts. It is difficult to understand the distribution described for the Argyll coast by Moss (I948), who maintains that with increase in exposure the numbers and sizes of vesicles for $F$. vesiculosus increase. Moss, however, defines the exposure of the coast in terms only of proximity to the open ocean, ignoring the many other factors which are important for algal populations, as, for example, the steepness of the rock surface, the direction of the slope and the presence or absence of outlying rocks which may take the first force of open sea breakers. It is not yet known whether sporelings from evesiculate plants will produce plants forming vesicles if grown under quieter conditions, but experiments are in progress to elucidate this point. However, on a gently sloping shore such as 
that of the experimental area at Port St Mary, it may be assumed that over relatively small areas environmental conditions will not vary appreciably. Since a proportion of the plants on the strip are evesiculate (Fig. $4 a$ ), and grow side by side with vesiculate plants, it may be justifiable to seek a different cause for this variation.

Two possible causes suggest themselves. Either (i) there is an evesiculate variety of $F$. vesiculosus which is independent of environmental conditions, or (ii) the plants are the result of crossing with an evesiculate species. However, as will be shown later, this problem probably resolves itself.

\section{Spiral Twisting of the Thallus}

This is another character which might depend on environmental conditions. Salt marsh forms of both $F$. spiralis and $F$. vesiculosus are frequently spirally twisted, and it has been suggested by Baker \& Bohling (I9I6) that this is due to a more rapid growth on the lower side kept moist by continued contact with wet mud, compared with the upper side which may be exposed to drying for many days at a time. F. spiralis might tend to become twisted because it normally grows at the highest level on the shore and at neap tides may be exposed for long periods. However, similar considerations apply to this character as to that of vesiculation of the thallus and the presence of both spirally and non-spirally twisted thalli in precisely the same locality suggests a different underlying cause.

\section{Receptacle Shape}

Receptacle shape may show considerable variation within a single species and especially is this so for $F$. vesiculosus. The appearance of a receptacle is determined by a number of factors of which the most important is probably the length in relation to the breadth. The breadth of a receptacle is partly determined by the breadth of the vegetative frond, and this may be influenced by environmental conditions. With narrowing of the frond, such as occurs with increase in exposure of the plant to severe wave action, the receptacle also becomes narrow until ultimately, on very exposed shores, it becomes completely cylindrical on inflation. Dichotomy of the receptacle is uncommon in $F$. spiralis, whereas in $F$. vesiculosus it may occur once or twice in each receptacle. The degree of inflation of the receptacle may also affect its appearance and this is accentuated in the presence of water of reduced salinity. Fucoids growing at the mouths of rivers or lying in trickles of fresh water running over the shore, have very large swollen receptacles. Thus for $F$. vesiculosus the ellipsoidal or ovate form usually found on sheltered coasts may become more or less cylindrical with increase in exposure, or enlarged by intake of fresh water under conditions of reduced salinity. It is, nevertheless, readily distinguishable from the rounded form of $F$. spiralis with its very conspicuous conceptacles. A population of $F$. vesiculosus was, however, found in the Isle of 


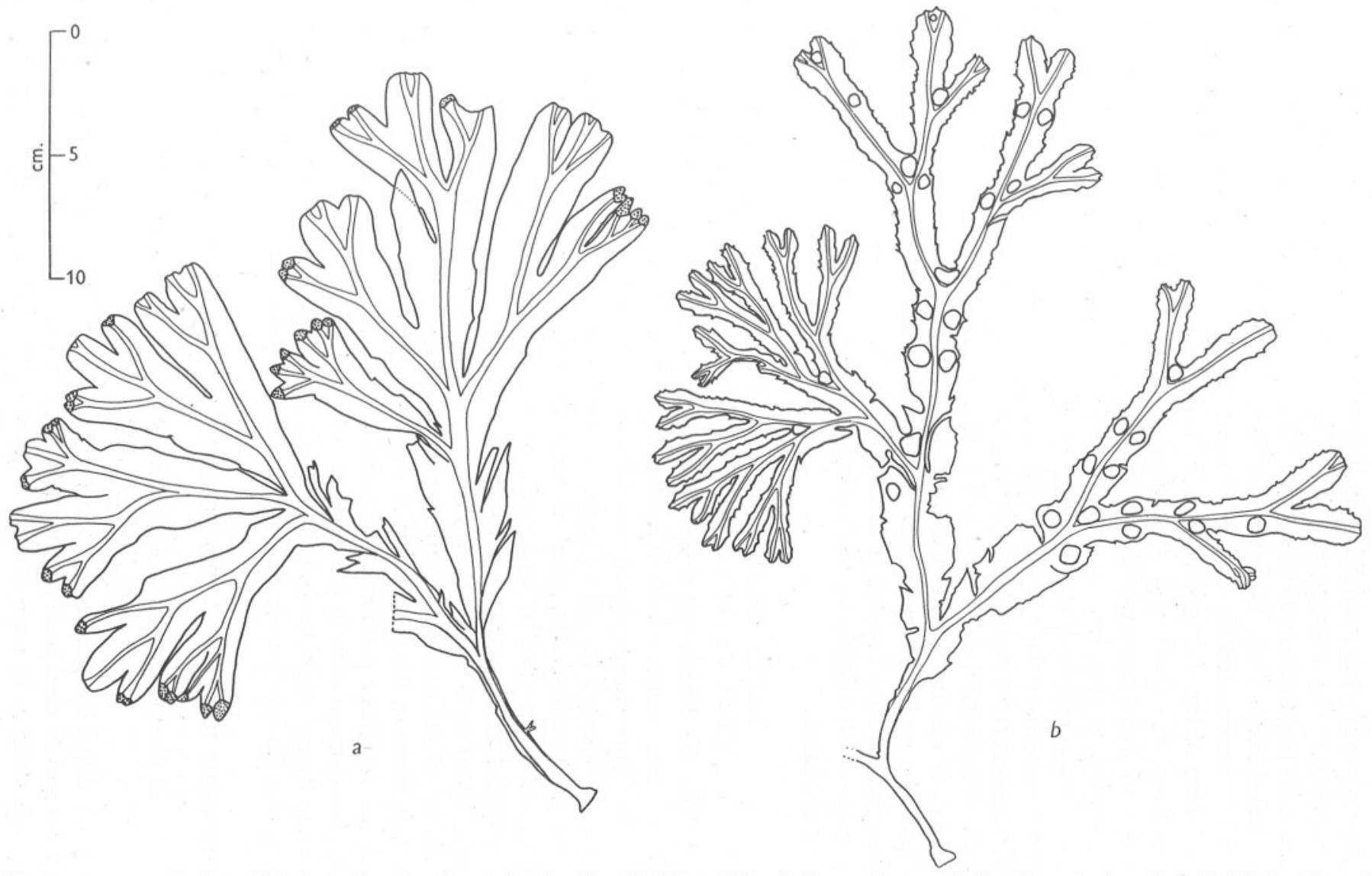

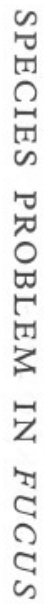

Fig. 4. $a$, an evesiculate plant from the experimental strip, Port St Mary, Isle of Man: Fucus spiralis $\times$ F. vesiculosus hybrid (?). b, plant of
Fucus with vesicles and a serrated edge from a Lundy Island population. a 
Man in one locality only, which had uniformly rounded receptacles, the plants corresponding to the description of $F$. vesiculosus L. var. sphaerocarpus J. G. Agardh. This population was found in a wide shallow depression on the upper part of the shore at Poyll Vaaish several miles distant from the experimental area and it seems unlikely that it would play any appreciable part in the establishment of the strip population. In using receptacle shape as a criterion in separating $F$. spiralis and $F$. vesiculosus there is to be considered the possibility of hybridization with Ascophyllum nodosum which also has somewhat rounded receptacles. Especially is this so in view of the fact that Williams (I899) obtained $50 \%$ development of hybrid sporelings using eggs of Fucus vesiculosus with antherozoids of Ascophyllum, and a plant was recorded as occurring in the Menai Straits with external characters intermediate between Ascophyllum and Fucus vesiculosus. Although this possibility was considered, it was not taken into account in the present discussion because there were no real indications that Ascophyllum had played any part in the formation of the strip vegetation. Even though conditions on the strip would now appear to be suitable for the settlement of Ascophyllum sporelings, none have yet appeared.

\section{Results of ANALysis of Hybrids BetweEn FUCUS VESICULOSUS AND FUCUS SPIRALIS}

Fig. 5 shows the results of the hybrid analysis between $F$. vesiculosus and $F$. spiralis for four samples from the strip vegetation taken from different tide levels. The uppermost sample was taken from M.H.W.N.T. and the lowest from a little below M.S.L. The diagrams show percentage frequency distributions for plants with index numbers ranging from $\circ$ (pure $F$. spiralis) to I4 (pure $F$. vesiculosus) The fifth histogram summarizes the distributions for the whole population. The pattern of the distribution is similar for the three upper samples: about $20 \%$ of $F$. spiralis, somewhat less than this of $F$. vesiculosus, and a range of intermediate forms between. In the lowest sample there is a marked decrease in the proportion of $F$. spiralis and an increase in that of $F$. vesiculosus. The large percentage of plants with an index number of to is due largely, but not entirely, to the presence of plants similar to $F$. vesiculosus in all respects except that they lacked vesicles. It is possible that these represent a genetically distinct variety but only cultural experiments could decide this point.

The gametes from the intermediate forms were fully formed and active.

FORMS INTERMEDIATE BETWEEN FUCUS VESICULOSUS AND FUCUS SERRATUS

One great difficulty preventing the completion of hybrid diagrams for $F$. vesiculosus and $F$. serratus is the fact that although the fruiting periods of the two species overlap to some extent, they are not sufficiently coincident; only 


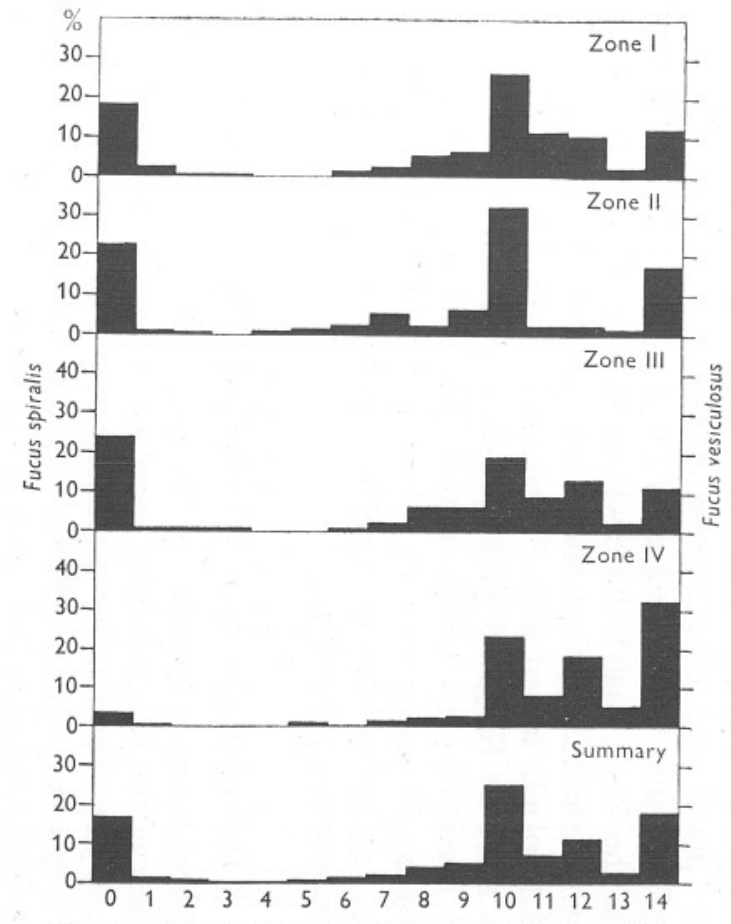

Fig. 5. Hybrid diagrams from Port St Mary Fucus population.

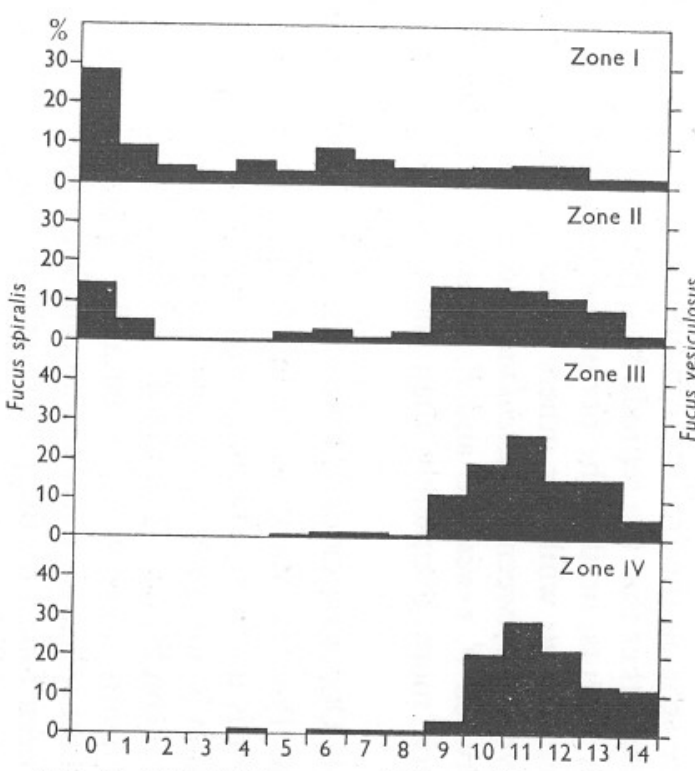

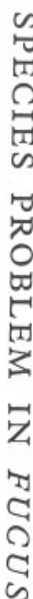

Fig. 6. Hybrid diagrams of River Mersey Fucus population. 
when all the plants are in the fruiting condition can the necessary distinctions be made. Plants intermediate between $F$. vesiculosus and $F$. serratus were found on the strip in the fruiting condition when $F$. vesiculosus was in fruit. This indicates either that the reproductive period of the hybrids extends over that of both parents, or that the period for some hybrids is coincident with that of $F$. vesiculosus while for others it may be coincident with that of $F$. serratus. Hybrids between $F$. vesiculosus and $F$. serratus were not as common as those between $F$. vesiculosus and $F$. spiralis, the fruiting periods of which overlap much more completely than those of the former pair of species.

\section{The Occurrence of Hybrids under Natural Conditions}

The strip at Port St Mary was a highly artificial area; an experiment of similar extent is unlikely to occur in nature and, as Anderson (1936) remarks, 'Hybridization is much more frequent in areas greatly disturbed by man than under natural conditions'. The question therefore arises as to whether, and if so how frequently, hybrids occur naturally. There is no doubt that hybrids among the three species of Fucus occur quite frequently on the open shore; many more have been found by the present authors since their existence has been recognized than had been previously noticed. Kniep (1925) suggested that the most favourable position for hybrids would be in the regions between the more sharply defined zones of the parent species, and it is in such regions that the majority of natural hybrids have been found on the Manx coasts. For example, plants with characters intermediate between those of $F$. vesiculosus and $F$. serratus occur frequently on the gently sloping rocks on the lower part of the Poyll Vaaish shore where the population is sparse and in a position in which the $F$. vesiculosus and $F$. serratus zones overlap. It is likely that the evesiculate plants mixed with $F$. spiralis in the upper part of the shore that are described by Knight \& Parke (I950) as F. vesiculosus var. evesiculosus Cotton and evesiculate by virtue of their high position on the shore, are hybrids between $F$. vesiculosus and $F$. spiralis. Present observations do not support the suggestion that there is a relation between vesiculation and vertical distribution on the shore.

\section{A Hybrid Population on the River Mersey Shore}

A second 'hybrid swarm' population has been found occurring naturally on the south bank of the River Mersey about 4 miles from Liverpool. Probably its presence in this region is due ultimately to the nature of the rock surface which is of very soft sandstone and can support only a limited size and weight of plant. Once the plants exceed a certain weight, the rock surface flakes away leaving a bare area open to recolonization. Thus the community is an open one and competition not as intense as it is on a firm rock surface. In addition, the fruiting period of Fucus spiralis is longer here and considerably overlaps 
that of $F$. vesiculosus. There is no period of the year at which plants cannot be found in the full fruiting condition, though possibly the extended fruiting period is more characteristic of the hybrids than of the parent species. Fig. 6 shows hybrid analyses for $F$. spiralis and $F$. vesiculosus from square metres of algal vegetation, for four positions on the shore ranging from the region of high water down to about M.S.L. The fucoid vegetation exists as a continuous cover only in the upper part of the shore. Lower down the population is scattered and consists only of short stunted plants. The water covering the plants at high tide is so muddy that the bulk of assimilation must be carried out at low tide when the plants are exposed and the degree of exposure at M.S.L. probably represents the minimum exposure to light required for effective assimilation (Burrows, 1947). The Mersey community is not a new one and the plants show a distinct zonation. F. spiralis is limited to the top of the shore as are also the hybrids approaching $F$. spiralis. Lower down only the hybrids approaching $F$. vesiculosus persist. An interesting feature of the population is that the hybrids are much more common than the parent species. It would appear that a hybrid approaching $F$. vesiculosus and not the parent species is best adapted to the conditions prevailing here. There were also other features of interest. All the plants which were evesiculate and dioecious were male. Many of the apparent hybrid plants had no vegetative apices: all had formed receptacles and so set a limit to the life of the plant. Probably on the fall of the receptacles new frondage would arise by proliferation, this condition being characteristic of many of the plants in this locality.

Stomps (I9II) found at Nieuport on the coast of Belgium, where the Chenal de L'Yser runs into the sea, a series of forms of $F$. vesiculosus and $F$. spiralis connecting the two species apparently precisely like the series on the River Mersey. He considered the question of the origin of these forms and ruled out hybridization on the basis of their distribution in his area. He remarked that our knowledge is still so limited that we cannot disregard a priori the possibility that the irregularities found on the shore may be due to hybridization, but he could not understand, if these aberrant individuals could so be explained, why they were more numerous in the canal region than on the sea coast.

Possibly here, as also on the River Mersey, their presence may be due to the open nature of the community. The evidence accumulated in this present investigation supports the view that such forms occur on the open coast under conditions of less acute competition from fully grown plants of the parent species, and supports Kniep's suggestion that it is this competition which prevents the establishment of hybrid plants in a fully developed open-shore zonation.

Stomps concluded from his observations that there is only one species of Fucus in place of the three, spiralis, vesiculosus and ceranoides (which he included), these being apparently habitat forms of a single species, 
environmental conditions deciding which hereditary characters shall be manifested in any one locality. Since over a large part of the rocky coast of Britain the characteristic fucoid vegetation is developed and in it the three taxonomic species remain distinct, there can be no advantage in disregarding this conception of them, i.e. as taxonomic species. Since up to the present it has not been possible to carry out cultural experiments on fucoids, mainly because of the difficulties of imitating intertidal conditions, the determination of the exact status of the three species must be assessed on somewhat circumstantial evidence. The results of the ecological experiment described have shown that there is no inherent sterility barrier among the three taxonomic species. This may also be true for other species of Fucus as, for example, $F$. ceranoides L., since hybrids between this species and F. spiralis have been reported (Sauvageau, 1908; Gard, 1910). Nothing has been found to run counter to the suggestion of Kniep (1925) that competition with the parent species prevents the development of hybrid plants in nature. Thus the barrier to complete merging of the species into one polymorphic species appears to be an ecological one, and it would appear that they are becoming isolated within specific tidal limits under the conditions prevailing in well-established open-shore vegetation. On the shore great changes in ecological conditions occur over relatively limited areas. A difference of I ft. in tide-level in the intertidal region of the shore may be equivalent to a large change in environmental conditions in terms of exposure to a drying atmosphere, changing light intensities, temperatures and the influence of water of variable salinity. It is likely that continued isolation in different parts of the intertidal region will ultimately lead to the development of other barriers, e.g. those of intersterility.

Using the ecotype terminology it would be difficult to know whether to regard these taxonomic species as ecotypes or ecospecies, since hybrid swarm populations may occur between them in nature, although, as far as we know, only rarely. The condition appears to be somewhat similar to that found for species of Silene among flowering plants from work carried out by Turrill and Marsden-Jones and reported by Turrill (1938). In north-west Europe ecological barriers alone keep them as distinct taxonomic units, and occasional hybrid swarm populations are found in nature.

Variation within the Fucus species may also occur along ecological gradients, one of which has been described, but many more probably exist, e.g. gradients of tidal depths, and reduction of the salinity of the water. Other types of variation also occur within the species which it is more difficult to connect with changes in environmental conditions. Whole populations may possibly be of hybrid origin. There has recently been found at Lough Ine in the West of Ireland a population showing the texture and serration of $F$. serratus, the spiral twisting and rounded and rimmed receptacles of $F$. spiralis and with somewhat irregular vesicular inflations. Similarly, a population exists on Lundy Island where plants possessing the vesicles of $F$. vesiculosus have 
serrated fronds characteristic of $F$. serratus (Fig. $4 b$ ). Species problems of this kind will probably arise for many different algae when more is known of their autecology and cytogenetical relationships.

\section{ACKNOWLEDGEMENTS}

We are indebted to Prof. J. H. Orton, F.R.S., and Mr N. S. Jones, who initiated the cleared-strip experiment, for permission to sample the resulting population. We also wish to thank Dr Margery Knight and Dr Mary Parke for reading the manuscript, and $\mathrm{Mr} \mathrm{R}$. B. Burrows whose co-operation made the work possible. Dr Parke kindly sent the material from Lundy Island.

\section{SUMMARY}

Characters used to distinguish Fucus spiralis L., F. vesiculosus L. and F. serratus L. are listed. Cross-fertilization between pairs of these species has been observed-independently by several workers.

Ecological habitats of the three species are described and the influence of competition on zonation is indicated. A Fucus population occurred on an area cleared of limpets at Port St Mary, Isle of Man, in which the majority of plants could not definitely be assigned to any one Fucus species.

Anderson's method of hybrid analysis was applied to samples from various levels on the area. The characters used in the analysis are listed and their status briefly discussed.

A direct relationship is recorded between vesiculation of the thallus of $F$. vesiculosus and the degree of exposure of the habitat to severe wave action. The extreme form for very sheltered localities is $F$. vesiculosus var. vadorum Aresch. and for exposed situations, F. vesiculosus var. evesiculosus Cotton. Great range in vesiculation in adjacent plants on the experimental strip is therefore due to hybridity or to a varietal form of $F$. vesiculosus.

Spiral torsion of the thallus in relation to environmental conditions is discussed.

Variation in receptacle shape in $F$. vesiculosus and F. spiralis is considerable; nevertheless, the use of this character in the hybrid analysis is justified.

Hybrid analysis between $F$. vesiculosus and $F$. serratus is difficult to carry out owing to the non-coincidence of fruiting periods of the parent plants.

The occurrence of hybrids in undisturbed populations in the Isle of Man is recorded.

A 'hybrid swarm' population by the River Mersey has been analysed and its significance discussed. An attempt has been made to assess the present status of the three species of Fucus. 


\section{REFERENCES}

Anderson, E., 1936. Hybridization in American Tradescantias. Ann. Missouri Bot. Gdn., Vol. 23, pp. 51 I-25.

BAKER, S. M. \& BoHLING, M. H., I9I6. On the brown seaweeds of the salt-marsh. II. Their relationships, morphology and ecology. fourn. Linn. Soc. London (Bot.), Vol. 43, pp. 325-80.

Burrows, E. M., I947. A biological study of Ascophyllum nodosum. Ph.D. thesis, London University.

Cotron, A. D., I9I2. Clare Island Survey. Marine Algae. Proc. Roy. Irish Acad., Vol. xxxI, Sect. I5, I78 pp.

Fritsch, F. E., I945. The Structure and Reproduction of the Algae. Vol. II. Cambridge.

Gard, N., I9IO. Sur un hybride des Fucus platycarpus et Fucus ceranoides. C.R. Acad. Sci., Paris, T. 15 I, pp. 888-90.

Jones, N. S., I948. Observations and experiments on the biology of Patella vulgata at Port St Mary, Isle of Man. Proc. Trans. Liverpool Biol. Soc., Vol. 56, pp. 60-77.

KNIEP, H., I925. Ueber Fucus-Bastarde. Flora, Vol. II8-I9, pp. 33I-8.

KnIGHT, M. \& PARKe, M., I950. A biological study of Fucus vesiculosus and Fucus serratus. Fourn. Mar. Biol. Assoc., Vol. xxIx, pp. 439-5I4.

Kylin, H., I907. Studien über die Algenflora der Schwedischen Westküste. Akad. Afhandl. Uppsala.

LOdGe, S. M., I948. Algal growth in the absence of Patella on an experimental strip of foreshore, Port St Mary, Isle of Man. Proc. Trans. Liverpool Biol. Soc., Vol. 56, pp. 78-83.

Moss, B., I948. Studies in the genus Fucus. I. On the structure and chemical composition of Fucus vesiculosus from three Scottish localities. Ann. Bot., N.S., Vol. XII, pp. 267-79.

Richard, J., I925. Les aerocystes et les boursouflures des Fucus. Rev. Aly., Vol. II, pp. I35-47.

Sauvageau, C., I908. Sur deux Fucus récoltés à Arcachon. Bull. Stat. Biol. Arcachon, Vol. II, pp. 65-224.

— 1909. Sur l'hybride des Fucus vesiculosus et Fucus serratus. C.R. Soc. Biol., Paris, T. 67, pp. 832-3.

Stomps, T. J., I9I I. Études topographiques sur la variabilité des Fucus vesiculosus L., platycarpus Thur., et ceranoides L. Rec. Inst. Bot. Léo Errera, Bruxelles, T. 8, pp. 326-77.

Thuret, G., I854. Recherches sur la fécondation des Fucacées, etc. Ann. Sci. Nat., Vol. IV, pp. I97-214.

TuRRILL, W. B., I938. The expansion of taxonomy with special reference to Spermaphyta. Biol. Rev., Vol. 13, pp. 342-71.

Williams, J. L.. 1899. New Fucus hybrids. Ann. Bot., Vol. I3, pp. 187-8. 